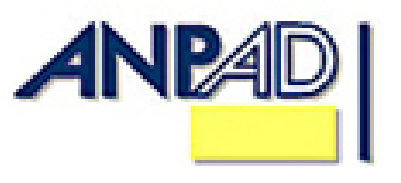
Disponível em
http://www.anpad.org.br/rac
RAC, Rio de Janeiro, v. 18, n. 5,
pp. 719-725, Set./Out. 2014
http://dx.doi.org/10.1590/1982-7849rac201410672
(oc) EY-No

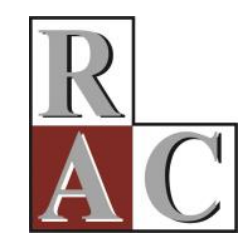

Documentos e Debates:

\title{
Réplica 2 - Por que Ler os Clássicos no Ensino e na Pesquisa em Administração?
}

Why Read Teaching and Research Classics in Management? 


\section{Introdução}

Ao ler o ensaio Por que Ler os Clássicos no Ensino e na Pesquisa em Administração?, compeli-me a fazer algumas considerações. O texto trata principalmente da formação do conhecimento, complexo, mas desenvolvido de modo didático e, dessa forma, de grande utilidade aos estudantes de pós-graduação e acadêmicos da área. O ensaio, no que se propõe e nos limites da epistemologia utilizada, trata sobre a condição da leitura dos clássicos de modo abrangente, fato que dificulta a sua crítica de um modo geral e nas suas especificidades. Ratifico cada uma das posições e interpretações dos autores a respeito das inquietações e afirmações sobre a utilização dos clássicos, buscando com isso um ponto de estímulo para a sua leitura. A natureza dialógica, reflexiva e construtivista dos autores é processo de compartilhamento e discussão. Entretanto, atento à finalidade desta seção da RAC, atrevo-me a fazer duas considerações e contra-argumentar, de modo preliminar, quanto a alguns pontos do texto, com o objetivo de expor ainda mais o documento original e ampliar a sua interlocução e debate. A primeira diz respeito ao propósito dos autores de não conceituar o que seja um texto clássico como meio de reflexão para o ensino e a pesquisa em Administração. A segunda refere-se às considerações epistemológicas que, no meu entender, merecem uma contínua reflexão sobre o tema.

Inicio minhas considerações entendendo que o principal propósito do ensaio é apresentar uma reflexão acerca dos autores clássicos utilizados para o ensino e a pesquisa em Administração, onde a abordagem adotada considera os processos sociais para a construção do conhecimento. Entendo também, pelo transcorrer do texto, que não há pretensão dos autores em conceituar o que seja um clássico ao reconhecerem a sua natureza socialmente construída. O texto como proposta ensaística enseja debater esse objetivo do ponto de vista do conceito de ensaio juntamente com a não intenção de se conceituar o que seja um texto clássico. Nesse sentido, recorro a Meneghetti (2011) ao afirmar que ensaio é forma de reflexão intelectual, em que os elementos da contradição são colocados em evidência no intelecto do ensaísta e dos seus interlocutores. Por meio dos diálogos, os lugares comuns e considerados seguros são substituídos pela dialética dos pensamentos dos envolvidos no ensaio com a própria mudança do mundo concreto. Por outro lado, para Vygotski (1934/1993), um conceito é uma descrição de modos de funcionamento espontâneos, em que suas possibilidades ensaísticas se orientam para a relação do conceito com outros conceitos, implicando em uma nova estrutura de generalizações configurada pela hierarquia coordenada de seus temas. O uso consciente e deliberado do conceito somente emerge quando passa a fazer parte desse sistema. Vygotski (1934/1993) estabelece ainda os conceitos científicos que, no início de seus desenvolvimentos, são esquemáticos e desprovidos da riqueza advinda da experiência, ganham uma melhor perspectiva para o seu entendimento e passam a fazer parte das práticas que lhes cabem em sua relação com os conceitos espontâneos.

Nesse sentido, é relevante estender e aprofundar a questão do que seja um clássico em termos de seu uso pelos docentes das diferentes áreas da Administração. Dessa forma, considero relevante ressaltar os conceitos espontâneos, suas contradições em relação aos modelos idealizados de que forma se constituem e formam uma hierarquia de seus temas. É sabido, pela extensa literatura educacional referente ao ensino e à pesquisa em Administração, que temos duas grandes áreas, ou seja, a funcional e a organizacional. A funcional, constituída pelas disciplinas de Marketing, Finanças, Produção, entre outras mais ou menos técnicas. Na área organizacional, temos Estudos Organizacionais e Estratégia. Essa segmentação se dá em função da necessidade de se contextualizar e entender a evidente emergência de questões das áreas funcionais, como, por exemplo, questionar se os clássicos das áreas funcionais são utilizados de modo mais utilitário e positivista do que os demais, afastando-os da abordagem reflexiva apregoada pelos autores. De forma mais ampla, nesse sentido, cabe questionar se, na área de Administração e das Ciências Sociais, há falácias no sentido de cada uma dessas disciplinas terem o seu estado da arte ao inserir ou refutar os clássicos enquanto orientadores de reflexões históricas e sociais. As posições assumidas dos professores e pesquisadores podem considerar trabalhos clássicos dos Estudos Organizacionais e de Estratégia como alheios aos Estudos Funcionais, ao mesmo tempo em que os professores de Estudos Organizacionais e Estratégias podem negar o uso da literatura Funcional. Observa-se um claro aumento das disciplinas de gestão em áreas alheias às da Administração, como nas Ciências Exatas. Observa-se que esses institutos enfatizam as áreas Funcionais da Administração como 
prioritárias nas suas ementas e, certamente, não incorporam em seu conteúdo os trabalhos clássicos dos Estudos Organizacionais. Na prática, estão distantes dos argumentos de Adler (2010), que, segundo esse autor, os estudos das organizações estão adequadamente estabelecidos tanto nos estudos organizacionais como nos profissionais, em que a sociologia e a economia permitem entender os passos das mudanças de nosso tempo e permitem energizar as pesquisas futuras no campo. Nessa abordagem, em defesa dessa interdisciplinaridade e dos autores, destaco que a única disciplina que permite de fato a ligação das áreas funcionais, para constituir o que chamamos de Ensino e Pesquisa em Administração, são as disciplinas de Estudos Organizacionais e de Estratégia, ao servirem como amálgamas de todas as demais. É nas disciplinas de Estudos Organizacionais e de Estratégia que os textos clássicos permitem maior reflexão sobre o nosso principal objeto de estudo e pesquisa, ou seja, a organização do passado, do presente e do futuro com o entendimento de seu contexto e de suas condições internas e suas relações fundamentais. Adler (2010) argumenta que os estudos organizacionais assim estão estabelecidos.

Dessa forma, em busca de um posicionamento mais pragmático como construção social e baseando-se em Eggins e Slade (1997), para explorar, pelo menos superficialmente, a produção do sentido do termo clássico, propus-me a buscar o que emerge do seu sentido e uso, enquanto literatura dos clássicos, a partir das perspectivas de alguns professores e pesquisadores que participam de cursos de mestrado e doutorado em Administração. Também intentei compreender o que os próprios autores recomendam, ou seja, "imersos nas práticas sociais que definem uma disciplina" (Meneghetti, Guarido, \& Azevêdo, 2014, p. 707).

\section{Diálogo com a Comunidade em Busca das Práticas da Leitura dos Clássicos}

Em questões abertas e espontâneas, enviadas por correio eletrônico a 100 colegas, sem a pretensão de estabelecer um parâmetro representativo dos mesmos, recebi 36 respostas. Pelo conteúdo do ensaio e das respostas, percebe-se que são poucos aqueles que possuem uma clara noção sobre o que seja um clássico e que o utilizam efetivamente enquanto referência historicamente situada e reflexiva. Esta constatação por si já justifica um esforço em definir, não obstante a sua complexidade, o que seja um texto clássico. Além disso, percebe-se que há diferentes termos utilizados com o mesmo significado de clássico, entre esses, um artigo seminal e o texto mainstream. A maioria das respostas negativas referentes ao seu uso apresentou argumentos, tais como:

"Não tenho como utilizar os clássicos em minha aula por falta de tempo. A disputa por leitura entre os professores do programa é grande. Consigo apenas utilizar textos mais atuais. Ou seja, os mainstrems da área." (Autor anônimo, comunicação pessoal, 17 de maio de 2013).

"Estabeleço leituras baseadas em papers seminais atuais." (Autor anônimo, comunicação pessoal, 19 de maio de 2013).

"Não utilizo. Os clássicos da minha disciplina apresentam apenas o início das ideias. Reconheço que são importantes, mas essas ideias foram revigoradas com o tempo pelas pesquisas empíricas." (Autor anônimo, comunicação pessoal, 19 de maio de 2013).

"Não utilizo. Geralmente, são mal traduzidos e desestimulantes em termos de aprendizagem." (Autor anônimo, comunicação pessoal, em 21 de maio de 2013).

. Ou simplesmente, "Não utilizo.” (Autor anônimo, comunicação pessoal, 21 de maio de 2013).

Há os que utilizam os clássicos, com os atributos apregoados pelos autores do ensaio, em um meio termo, como livro didático sem a aderência histórica contextualizada não progressiva, como fenômeno transversal e reflexiva enquanto instituições sociais, assim como:

"Coloco os clássicos como primeira leitura para apresentar a conceituação que irei utilizar na disciplina." (Autor anônimo, comunicação pessoal, 18 de maio de 2013). 
"Os clássicos que utilizo são aqueles obrigatoriamente utilizados por todos os professores dessa disciplina ... passo como leitura complementar." (Autor anônimo, comunicação pessoal, 19 de maio de 2013).

Por sua vez, a sua natureza historicamente situada, enquanto representação social visando à compreensão dos fenômenos sociais ali representados, pode ser observada nos seguintes depoimentos, os quais considero relevantes e representativos de outros respondentes e, assim dou destaque às autorias:

\section{Do Professor Carlos Osmar Bertero -}

Utilizo os clássicos e os considero um texto que exerceu impacto duradouro no campo de conhecimento respectivo há algum tempo ou um texto cujo conteúdo foi acabou por ser incorporado aos conhecimentos centrais ou fundamentais de uma área. São fontes permanentes de inspiração e de reposicionamento. Lembro-me de um musicólogo que dizia ouvir Mozart e reler sua partitura sempre que fosse tentado pelo mau gosto. Os clássicos são um vínculo com o passado e uma ponte para as perspectivas futuras. Se for para a filosofia verá que nunca se pode deixar de reler os gregos. Já houve quem dissesse que toda a filosofia ocidental não é mais que um longo comentário das obras de Platão e Aristóteles. (C. O. Bertero, comunicação pessoal, 17 de maio de 2013).

\section{Do Professor Maurício Serva -}

O clássico é o texto que mudou o curso de uma dada ciência, sendo adotado por muito tempo e reconhecido internacionalmente por esse feito pelos cientistas do campo correspondente. É passagem obrigatória na formação de uma especialidade científica por ter dado uma contribuição epistemológica capital para o desenvolvimento de uma dada ciência. (M. Serva, comunicação pessoal, 17 de maio de 2013).

\section{Da Professora Ana Guedes -}

Entendo os clássicos ou seminais enquanto atemporais por sua capacidade crítica e reflexiva, por possibilitar o entendimento e/ou explicação de um determinado fenômeno na sua complexidade. Quando perdem sua capacidade de compreensão e explicação do fenômeno, são reproduzidos, citados, adotados como clássicos, sem que se reconheçam os desdobramentos teóricos do tema, abordagem, área de conhecimento. Ao final, tornam-se dogmáticos porque perdem a essência da teorização e reflexão analítica crítica inerente aos fenômenos sociais. (A. Guedes, comunicação pessoal, 20 de maio de 2013).

\section{Do Professor Carlos Alberto Gonçalves -}

Os clássicos são registros considerados relevantes por especialistas em um dado campo de conhecimento organizado. Não podemos ignorá-los sob o risco de fazer abordagens piores na fase do estado da arte. Melhoram a visão panorâmica do saber em dado campo temático para o cientista. Se um clássico é parte da história da ciência, não significa que não podem retomar os seus princípios nos fenômenos atuais. Até mesmo inovações de ruptura nos saberes tecnológicos que descontinuaram tratamentos por permitir reflexões dialéticas ou mesmo despertar necessidade de sua permanente verificação (Popper). No diálogo entre o moderno e o pós-moderno, o antigo e o novo, devemos cuidar de mostrar saberes como princípios para orientar as gerações, evoluir sem dizer que o passado de ontem pode ser o presente novamente. O tempo absoluto não volta, mas alguém disse que o tempo é também relativo, e foi um clássico. (C. A. Gonçalves, comunicação pessoal, 20 de maio de 2013).

\section{Da Professora Queila Matitz -}

Um clássico é original e referência para outros autores e pesquisadores que estudam esse mesmo tema. Permitem a verificação e a análise de conceitos originais sem a interferência de traduções ou interpretações mediadoras. Um dos problemas no uso dos clássicos diz respeito à sua diacronia 
conceitual, ou seja, a leitura de um texto muito antigo ou escrito em outro contexto cultural pode conduzir a interpretações enviesadas ou contaminadas por visões de mundo contemporâneas. Dessa forma, corre-se o risco de atribuir ao autor ideias ou intenções que não foram pensadas ou previstas por ele. (Q. Matitz, comunicação pessoal, 21 de maio de 2013).

\section{Da Professora Natália Rese -}

Os clássicos nos possibilitam remontar o que já sedesenvolveu, de contextualizar descobertas, de evidenciar trajetórias e principalmente de embasar lacunas que merecem ser exploradas e descobertas. Corremos um grande risco de redundância científica ao abandonar os clássicos ou valorizar somente textos que os reinterpretam, visto que cada leitura evidencia, sob o meu ponto de vista, o sentido que cada sujeito dá a ela. (N. Rese, comunicação pessoal, 22 de maio de 2013).

Do Professor Antonio Gelis Filho, também em consonância com os autores do ensaio, afirma -

Utilizo os clássicos e entendo que Ítalo Calvino apresenta 14 definições do que seja um clássico - seria apenas aquilo que não pode não ser chamado de clássico? 'Clássico', nesse sentido, seria o ponto inatingível de uma assíntota intelectual: pode ser encontrado e identificado como tal, mas apenas em um infinito além do horizonte de observação possível, resultando em uma inevitável frustração de 'nunca podermos atingir a essência clássica dos clássicos'. Existe a possibilidade de estarmos convivendo com clássicos antes de eles serem considerados como tais. Há alguma implicação disso para a ciência da administração? (A. F. Gelis, comunicação pessoal, 26 de maio de 2013).

Do Professor Emil Hoffmann - "Os clássicos permitem entender os pressupostos das ideias que usamos atualmente. Ou seja, conhecer a fonte do saber atual. Sem eles, o ensino fica demasiadamente ideológico." (E. Hoffmann, comunicação pessoal, 22 de maio de 2013).

Do Professor Paulo Hayashi - "São inspiradores e desafiantes. São e foram inovadores em algum momento. Representam o estado da arte em seu tempo e estavam além do seu tempo. Representam pensamentos profundos e argumentos claros." (P. Hayashi, comunicação pessoal, 24 de maio de 2013).

Assim, entendo que esses diálogos representam uma pequena parte do estado da arte de algo que precisa ser mais bem-compreendido e, provavelmente, também represente a afirmação legítima no uso do conceito de clássico ou seminal enquanto fenômeno objetivo, dessa forma, afastando-se pelas questões utilitaristas feitas aos respondentes, mas, pelas respostas obtidas, sem deixar de lado a fluidez expansiva de Calvino (1993), citado pelos autores. Provocação à parte, minha segunda consideração diz respeito às diferentes epistemologias observadas nas afirmações dos autores e dos respondentes.

\section{Diferentes olhares para os clássicos}

Durant e Vaara (2006) desenvolveram um estudo bibliográfico sobre a epistemologia positivista, construtivista, realista e pragmática em estudos de estratégia. Adaptado ao argumento desses autores, cada uma dessas abordagens pode possibilitar proposições distintas para a leitura dos clássicos. Observo que os autores do ensaio se referem ao texto clássico sobre uma perspectiva construtivista carregada, corretamente por assim dizer, de abstrações e significados subjetivos. Entretanto o estado da arte com os significados de cada uma das posturas epistemológicas citadas pode representar diferentes perspectivas de relevância e utilidade, assim como: - um clássico é um texto que inicia uma ideia; - o clássico é um conhecimento organizado, ou ainda, - o clássico é fruto de uma construção social. Esses relatos podem ser considerados como mais ou menos verdadeiro para diferentes posturas epistemológicas.

Para os usuários com tendência positivista, o texto clássico pode representar um objeto de estudo existente, real. Tem a expectativa da representação de modelos empíricos que revelam as relações causais, preferencialmente, com a devida validação. O foco corresponde à construção e ao uso de medidas e estimativas de modelos. Pelo histórico da área, abrange grande parte dos envolvidos na 
formação de Administradores. Dessa forma, é esperada uma definição mais precisa dos conceitos apresentados nos clássicos e sua utilidade contemporânea para contribuir com a explicação de fenômenos observáveis atuais.

Para os usuários do texto com tendência construtivista, como abordado pelos autores do ensaio, os textos representam as condições sociais de seu contexto histórico e a construção discursiva com o uso de vários métodos de análise social. A análise do discurso tem papel central com ênfase na reflexibilidade. Seus objetos são constituídos socialmente ou invenções dos pesquisadores ou pensadores. A leitura do clássico é percebida como construção de um argumento legitimado e contextualizado com observações sobre suas implicações ideológicas. Abrange atualmente parte dos envolvidos na formação de Administradores pela influência das disciplinas das ciências sociais e organizacionais. Dessa forma, é esperada uma definição que represente a relação entre o contexto e o texto que contribua na explicação e na reflexão de fenômenos complexos.

É expectativa dos textos clássicos, pelos pesquisadores, com o olhar do Realismo Científico, um objeto de pesquisa, tal qual no positivismo, existente e real. Entretanto sua diferença reside na consideração de que o conhecimento é falível e não pode ser estudado ou observado diretamente por sua fluidez e complexidade. Dessa forma, a observação dos fenômenos se dá pelos seus mecanismos geradores, ou aqueles fatores que colaboram ou prejudicam o fenômeno observado. Assim, esse desafio abrange grande parte dos acadêmicos envolvidos em pesquisa na área de Administração que utilizam a abordagem da ação, na qual se espera uma explicação mais clara dos objetos complexos que se modificam sob a ótica dos seus fatores intervenientes e moderadores.

Os usuários do texto com tendência ao Pragmatismo esperam explorar conceitos de valor utilitário potencial. Essa expectativa diz respeito a conceitos com utilidade suficiente para ajudar a melhor compreender ou gerir organizações. Abrange parte dos envolvidos com atividades acadêmicas e profissionais na formação de Administradores. Apesar de concentrar-se no senso comum e nas regras simples, espera-se no clássico uma definição mais precisa dos conceitos e orientados para a geração de conhecimento socioeconômico.

Dessa forma, diferentes posicionamentos dos respondentes das questões de uso dos clássicos pelos professores e pesquisadores da área de Administração estimularam sua observação sob diferentes lentes epistemológicas. Discussão atual tem sugerido a escolha, pelos pesquisadores, de uma das duas vertentes, a positivista somada à realista, ou a construtivista. Aparentemente, essa condição, pelas respostas obtidas nos questionários, parece ser verdadeira. Todavia Durant e Vaara (2006) argumentam que essa escolha não é tão simples pelas complexas e abrangentes particularidades de cada uma das quatro vertentes apresentadas. Fato é que os clássicos são e devem ser utilizados por todas as vertentes. Relevante destacar o trabalho de Fonseca e Machado-da-Silva (2010) Indivíduo, Organização e Ambiente: Bases para a Conversação entre Três Perspectivas de Estudo da Estratégia em Organizações, em que analisam a possibilidade de conversação entre as diferentes epistemologias dos estudos em Estratégia.

A falta de entendimento sobre as diferentes expectativas do campo sobre a leitura dos clássicos enquanto referência epistemológica pode conduzir ao afastamento dos clássicos, cuja resultante, na formação de novos professores e alunos, poderá ser considerada como ensino sem reflexão e que, por isso, deve ser foco de constante debate pela comunidade acadêmica da Administração. É sob esse prisma que as duas abordagens propostas por este texto se complementam. A necessidade de um conceito de clássico que oriente o seu debate e o seu uso enquanto formador do conhecimento reflexivo e crítico, mas que seja abrangente o suficiente para atender às expectativas dos diferentes olhares epistemológicos.

\section{Considerações Finais}

O presente trabalho foi idealizado pela inquietação produzida pelo ensaio Por que Ler os Clássicos no Ensino e na Pesquisa em Administração?. Procurei, neste texto, apresentar a minha 
própria opinião. Diferentemente dos autores, proponho o resgate do conceito enquanto instrumento de construção social e, ao mesmo tempo, racional. Essas considerações sugerem que o clássico é fenômeno único, a cargo de seus idealizadores, mas, também, oriundo da dinâmica de interação entre os seus diferentes usuários e observadores, envolvidos por condições históricas e socioeconômicas distintas, conforme exemplificado pelas declarações produzidas pelos professores e pesquisadores dos Programas de Pós-Graduação em Administração, que se propuseram a gentilmente responder ao questionário. Assim, espera-se que a sua explicação conceitual enquanto fenômeno amplo e complexo possa ser capaz de estimular a leitura dos clássicos como texto obrigatório, e não como leitura complementar.

Concluindo, sugiro que os autores do ensaio ou outros sejam estimulados pelo desafio de tentar produzir um conceito de clássico que seja suficientemente abrangente e seja capaz de atender às diferentes expectativas e a uma conversação entre os diferentes posicionamentos epistemológicos. Entretanto a única certeza que resta é que os clássicos são de fundamental importância sob qualquer uma delas.

\section{Referências}

Adler, P. S. (2010). The oxford handbook of sociology and organization studies: classical foundations. GB: Oxford Handbooks.

Calvino, I. (1993). Por que ler os clássicos? (5a ed.). São Paulo: Companhia das Letras.

Durant. R., \& Vaara, E. (2006). A true competitive advantage? Reflection on different epistemological approaches to strategic research. Recuperado de www.hec.edu/heccontent/download/4765/130926/version/2/.../CR838.pdf

Eggins, S., \& Slade, D. (1997). Analysing casual conversation. London: Cassell.

Fonseca, V. S., \& Machado-da-Silva, C. L. (2010). Conversação entre abordagens da estratégia em organizações: escolha estratégica, cognição e instituição [Edição Especial]. Revista de Administração Contemporânea, 14, 51-75. Recuperado de http://www.scielo.br/pdf/rac/v14nspe/a04v14ns.pdf. doi: 10.1590/S1415-65552010000600004

Meneghetti, F. K. (2011). Tréplica - O que é um Ensaio-Teórico? Tréplica à professora Kazue Saito Monteiro de Barros e ao professor Carlos Osmar Bertero. Revista de Administração Contemporânea, 15(2), 343-348. Recuperado de http://www.scielo.br/pdf/rac/v15n2/v15n2a13.pdf. doi: 10.1590/S1415-65552011000200013

Vygotski, L. S. (1993). Pensamiento y lenguaje. In A. Alvarez \& P. Del Rio (Eds.), Problemas de psicologia general - Obras Escogidas (Vol. II, pp. 11-348) Madri: Visor. (Obra original publicada em 1934) 